\title{
COVID-19, de novo seizures, and epilepsy: a systematic review
}

\author{
Ali A. Asadi-Pooya ${ }^{1,2}$ (D) $\cdot$ Leila Simani $^{3} \cdot$ Mina Shahisavandi $^{1} \cdot$ Zohreh Barzegar $^{1}$
}

Received: 22 September 2020 / Accepted: 20 November 2020 / Published online: 25 November 2020

(C) Fondazione Società Italiana di Neurologia 2020

\begin{abstract}
Objective We discuss the evidence on the occurrence of de novo seizures in patients with COVID-19, the consequences of this catastrophic disease in people with epilepsy (PWE), and the electroencephalographic (EEG) findings in patients with COVID-19. Methods This systematic review was prepared according to the recommendations of the Preferred Reporting Items for Systematic Reviews and Meta-Analyses statement. MEDLINE, Scopus, and Embase from inception to August 15, 2020 were systematically searched. These key words were used: "COVID" AND "seizure" OR "epilepsy" OR "EEG" OR "status epilepticus" OR "electroencephalography".

Results We could identify 62 related manuscripts. Many studies were case reports or case series of patients with COVID-19 and seizures. PWE showed more psychological distress than healthy controls. Many cases with new-onset focal seizures, serial seizures, and status epilepticus have been reported in the literature. EEG studies have been significantly ignored and underused globally.

Conclusion Many PWE perceived significant disruption in the quality of care to them, and some people reported increase in their seizure frequency since the onset of the pandemic. Telemedicine is a helpful technology that may improve access to the needed care for PWE in these difficult times. De novo seizures may occur in people with COVID-19 and they may happen in a variety of forms. In addition to prolonged EEG monitoring, performing a through metabolic investigation, electrocardiogram, brain imaging, and a careful review of all medications are necessary steps. The susceptibility of PWE to contracting COVID-19 should be investigated further.
\end{abstract}

Keywords Coronavirus $\cdot$ COVID-19 $\cdot$ EEG $\cdot$ Epilepsy $\cdot$ Seizure

\section{Introduction}

Since late 2019, the world has been experiencing a catastrophic pandemic of a new coronavirus disease (COVID-19) caused

Ali A. Asadi-Pooya

aliasadipooya@yahoo.com

Leila Simani

1.simani62@gmail.com

Mina Shahisavandi

shahisavandimina@gmail.com

Zohreh Barzegar

zohrehbarzegar1375@gmail.com

1 Epilepsy Research Center, Shiraz University of Medical Sciences, Shiraz, Iran

2 Jefferson Comprehensive Epilepsy Center, Department of Neurology, Thomas Jefferson University, Philadelphia, PA, USA

3 Skull Base Research Center, Loghman Hakim Hospital, Shahid Beheshti University of Medical Sciences, Tehran, Iran by SARS-CoV2-[1]. Previous outbreaks of coronaviruses consist of the severe acute respiratory syndrome (SARS) in 2002 and the Middle East respiratory syndrome (MERS) in 2012 [2] Coronaviruses primarily target the human respiratory system. However, they have also been associated with neurological manifestations (e.g., seizures, change in mental status, and encephalitis):[2,3]. Neurotropic and neuroinvasive capabilities of coronaviruses have been described before[4].

The signs and symptoms of COVID-19 infection often appear after an incubation period of about five days [1]. The most frequent manifestations at the onset of COVID-19 illness are fever, cough, loss of smell and taste, and fatigue; other manifestations may include headache, hemoptysis, diarrhea, and dyspnea. In patients with severe disease, pneumonia, acute respiratory distress syndrome, organ failure, metabolic derangements, and acute cardiac injury may happen [1]. It is reasonable to expect that some patients with COVID-19 develop seizures as a consequence of hypoxemia, organ failure, metabolic derangements, drug-drug interactions, or even brain damage that may occur in patients with COVID-19 $[2,3,5]$. On the other hand, information on the susceptibility of people 
with epilepsy (PWE) to contracting COVID-19 and the consequences and challenges of this catastrophic disease in PWE are scarce.

In the current systematic review, we will discuss the evidence on the occurrence of de novo seizures in patients with COVID19 (the types of seizures and the etiology), the consequences, and challenges of this catastrophic disease in PWE (e.g., access to care and seizure control), and finally, the electroencephalographic (EEG) findings in patients with COVID-19. We will also provide suggestions to tackle the abovementioned issues based on the best available evidence.

\section{Methods}

This manuscript was prepared according to the recommendations of the Preferred Reporting Items for Systematic Reviews and Meta-Analyses (PRISMA) statement [6, 7] (Fig. 1 and Table 1). MEDLINE (accessed from PubMed), Scopus, and Embase from inception to August 15, 2020 were systematically searched for related published articles. In all electronic databases, the following search strategy was implemented and these key words (in the title/abstract) were used: "COVID" AND "seizure" OR "epilepsy" OR "EEG" OR "status epilepticus" OR "electroencephalography". Articles written in English were all included. To ensure literature saturation, the authors scanned the reference lists of the included studies or relevant articles identified through the search. All authors participated through each phase of the review independently (screening, eligibility, and inclusion). They obtained full reports for all titles that appeared to meet the inclusion criteria or where there was any uncertainty. They resolved any disagreement through discussions. Neither of the authors were blind to the journal titles nor the study authors or institutions.

The following data were extracted from the included studies: study authors, study location, study designs, main results, and limitations. The methodological quality of the included studies was assessed by the authors. The class of evidence was defined following the American Academy of Neurology criteria for classification of evidence in studies of causation (Appendix, Table 5) [8].

\section{Standard protocol approvals, registrations, and patient consents}

The Shiraz University of Medical Sciences Institutional Review Board approved this study and systematic review.

\section{Results}

Through the search strategy, we could identify 62 related manuscripts (Tables 2, 3, and 4) [9-70]. Only one paper provided class 2 evidence and 11 papers provided class 3 evidence; the rest of the publications provided class 4 evidence. Many studies were case reports or case series of patients with COVID-19 and seizures. The rest of the publications were surveys or observational studies (Tables 2, 3, and 4). Below, we summarize the results of this systematic review:

1.1. Epilepsy related papers (Table 2): One cross-sectional study of 21 patients with active epilepsy and COVID-19 out of 1537 patients $(1.4 \%)$ with level 2 of evidence showed that the cumulative incidence of COVID-19 in people with epilepsy was higher compared with the population without epilepsy ( $1.2 \%$ vs. $0.5 \%)$ [9]. Furthermore, the total case fatality rate was higher in PWE compared to patients without active epilepsy (23.8\% vs. $3.6 \% ; p<0.001)$ [9]. However, these results were obtained based on a small number of PWE (21 persons) and should be interpreted with caution. In addition, in another study, among 5700 PWE, who were managed at the studied centers, only 14 people tested positive for SARS-CoV-2, without obvious impacts on their epilepsy [18]. Six surveys of PWE showed that many people perceived significant disruption in the quality and availability of care to them (31 to $95 \%$ ), as well as increased stress and social isolation, and increase in seizure frequency (6 to $35 \%$ ) since the onset of the pandemic [11, 12, 14-17]. One observational comparative study confirmed that PWE showed more psychological distress than healthy controls, and they spent significantly more time following the COVID-19 outbreak news [13]. Finally, four studies showed that telemedicine may improve access to specialized care for PWE in these difficult times [10, 20-22]. The development of an epilepsy electronic patient portal may promote improved patient-clinician partnerships and facilitate patient self-management [23]

1.2. Seizure-related papers (Table 3): While one retrospective study reported no seizures in 304 patients with COVID-19 [25], multiple studies refuted that finding [24, 26-29]. Furthermore, many cases with new-onset focal seizures, serial seizures, and status epilepticus have been reported in the literature [30-49, 51, 63]. The etiology of seizure(s) in the reported patients was most likely multifactorial, as many of them had comorbidities (e.g., diabetes and kidney disease), multiorgan failure, metabolic derangements, hypoxemia, etc. In addition, all these patients received many medications [33-47]. However, some of the patients had specific neurological problems (e.g., encephalitis [33, 40, 70] and cerebrovascular 
events $[38,42,43,51,59])$. SARS-CoV-2 RNA was detected in the cerebrospinal fluid (CSF) in two patients $[40,53]$; however, many other studies that tested for this had negative results $[36,42$, $44,46,52,59,60,64,67,70]$. It should be emphasized that many centers did not investigate the patients with COVID-19, who had seizures, thoroughly. For example, many patients did not have EEG exams, and in a significant number of them CSF analysis and even brain imaging studies were not performed.

1.3. EEG-related papers (Table 4): While change in mental status has frequently been reported in patients with COVID-19 [26, 27, 55, 60, 65, 66, 70], and while there are many reports on clinical and subclinical seizures and status epilepticus in these patients [33-47, 63, 66], EEG studies have been significantly ignored and underused in these patients globally. Three studies showed that EEG services have been significantly disrupted by the pandemic of COVID-19 [18, 19, 57]. Three other studies showed that many of the patients with COVID-19 and encephalopathy/seizures had epileptiform discharges/seizures in their EEG [29, $54,55]$. One study of two patients with COVID19 and encephalopathy suggested a unique EEG pattern with continuous, slightly asymmetric, monomorphic, diphasic, delta slow waves with greater amplitude over both frontal areas and with a periodic organization [58]. Finally, two studies suggested that quantitative EEG (QEEG) features may be useful for diagnosis and prognostication of the neurological outcome in critically ill patients with COVID-19 [61, 62]. While studies investigating EEG in patients with COVID-19 did not find a consistent and specific neurophysiological pattern in critically ill patients, the authors should describe the EEG findings more appropriately, adhering to the standardized terminologies, in future studies [71].

\section{Discussion}

The evidence on the susceptibility of PWE to contracting COVID-19 and the consequences of this catastrophic disease in PWE is scarce. A recent systematic review suggested that patients with pre-existing neurological disorders (including epilepsy) and COVID-19 may develop exacerbation of their neurological problems and also severe COVID-19 [72]. This significant concern should be addressed in the future through well-designed prospective cohort studies with all relevant confounders controlled. However, evidence showed that many PWE perceived significant disruption in the quality and availability of care to them, and some people reported increase in their seizure frequency since the onset of the pandemic [11, $12,14,16,17]$. Previous global experiences confirm this piece of evidence. A study of 227 PWE during the SARS outbreak in 2003 in Taiwan demonstrated that $22 \%$ of them did not receive their medications due to loss of contact with their healthcare providers; $12 \%$ of them experienced seizure control status worsening [73]. In addition, many PWE may have increased stress and social isolation, even more than that in others, during such circumstances as COVID-19 pandemic [12-15]. During pandemics and other difficult and catastrophic circumstances (e.g., wars and mass displacements), healthcare workers should focus not only on seizure control status of their patients, but also on the mental health of PWE [13]. In such times, stress is associated with increased seizures in PWE [11], and stress management strategies may play a significant role in helping these patients cope with their ongoing problems more successfully. Research shows that people who follow COVID-19 news the most, experience more anxiety and stress $[74,75]$. Healthcare providers should advise their patients to avoid following COVID-19 news frequently. In addition, it might be helpful to use digital communication methods such as social networks to prevent social isolation [75]. Similarly, many patients with epilepsy may have depressive symptoms, particularly during such difficult times, and several factors related to epilepsy (e.g., seizure frequency and quality of life) are significantly correlated with depressive symptoms [76]. Therefore, it is helpful to screen all PWE for anxiety, stress, and depression, and treat any psychological problems that patients may have, particularly during a pandemic or other difficult circumstances.

Telemedicine is a viable and helpful technology that may improve access to the needed care for PWE in these difficult times $[10,20,22]$. During a pandemic such as what we are experiencing now, telemedicine, particularly video consultations, ought to be promoted in order to reduce the risk of disease transmission [77]. Telemedicine has been shown to improve access to care for PWE in difficult circumstances (e.g., people living in rural areas) [78]. However, many countries do not have the infrastructure or the regulatory frameworks to authorize, integrate, and reimburse telemedicine services [77].

Another important issue is the occurrence of new-onset seizures in people with COVID-19. While seizure is not a common manifestation of COVID-19, it may happen in a variety of forms (e.g., focal motor, tonic-clonic, convulsive status epilepticus, and nonconvulsive status epilepticus) [28, 30-47]. On the other hand, many patients with severe COVID-19 may have changes in their mental status [26, 27]. When visiting a patient who is in a critical medical condition 
Fig. 1 Preferred Reporting Items for Systematic Reviews and Meta-Analyses (PRISMA) flow diagram of the study

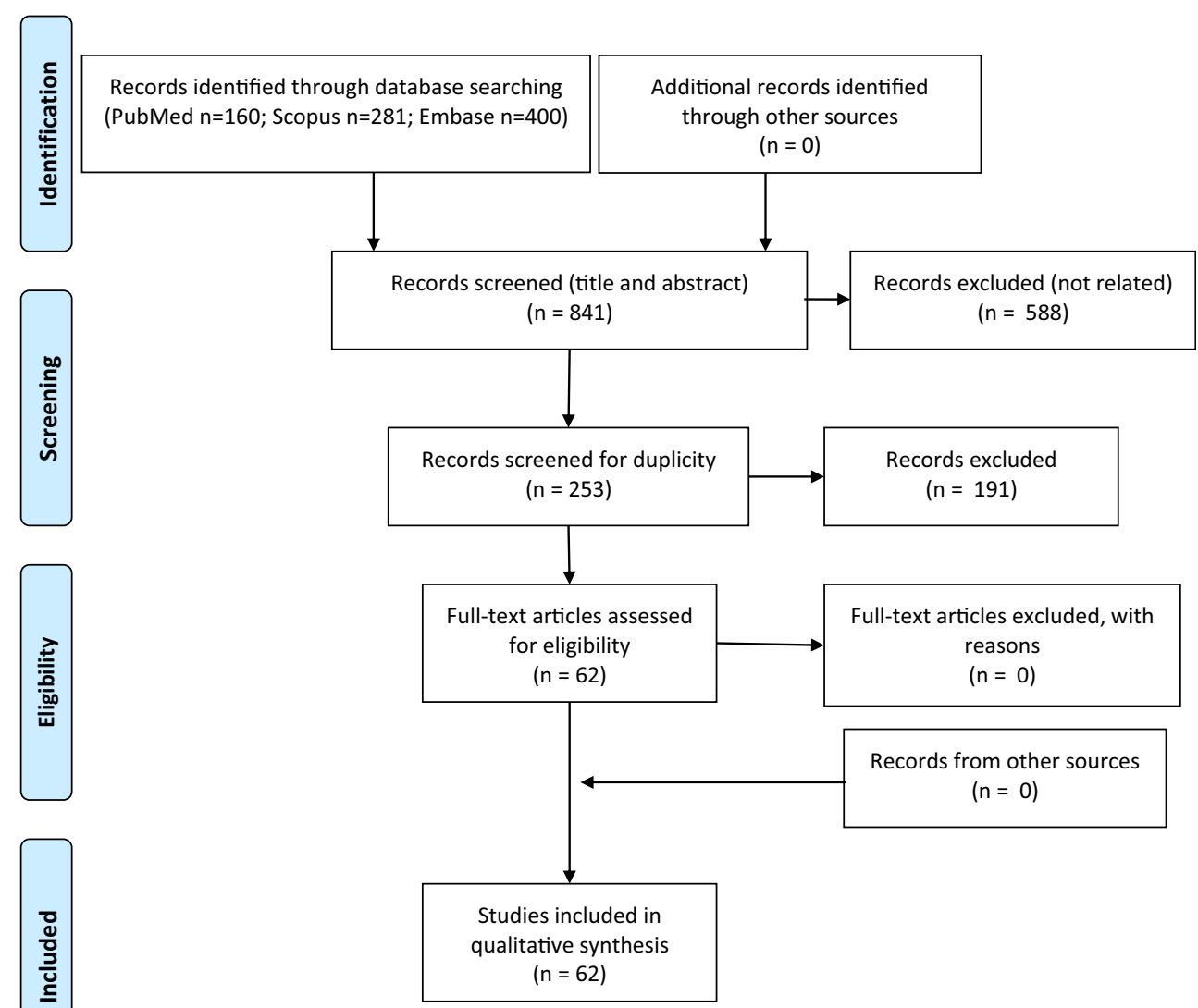

and has a change in mental status, the treating healthcare professional should make sure that nonconvulsive status epilepticus is not a part of the clinical scenario. Prolonged EEG monitoring is required in these circumstances [3]. Electroencephalography is probably one of the most useful tests to help identify the etiology of seizures and/or change in mental status in critically ill patients, including those with COVID-19; and at the same time, it is probably the most neglected test so far in the management process of these patients globally. It is helpful to describe the EEG findings in a systematic and consistent manner in order to characterize any possible distinguishing and/or prognosticating EEG patterns in patients with COVID-19. Finally, quantitative EEG may also be useful for diagnosis and prognostication of the neurological outcome in critically ill patients with COVID-19 [61, 62].

Seizures may happen as a consequence of hypoxia, metabolic derangements, organ failure, medications, or brain damage that could happen in people with COVID-19 [3, 5]. If a patient with COVID-19 develops a seizure, one should try to

Table 1 The search keywords included "COVID" and "Epilepsy/Seizure" in the title/abstract

\begin{tabular}{|c|c|c|c|c|c|c|}
\hline \multirow[b]{2}{*}{ Keywords (\& COVID) } & \multicolumn{2}{|c|}{ Medline (PubMed) } & \multicolumn{2}{|l|}{ Scopus } & \multicolumn{2}{|l|}{ Embase } \\
\hline & Primary hints & Relevant articles & Primary hints & Relevant articles & Primary hints & Relevant articles \\
\hline Epilepsy & 55 & 23 & 85 & 25 (24 duplicates)* & 154 & 28 (28 duplicates) \\
\hline Seizure & 42 & 23 (11 duplicates) & 112 & 28 (21 duplicates) & 122 & 22 (22 duplicates) \\
\hline EEG & 29 & 16 (6 duplicates) & 26 & 5 (5 duplicates) & 50 & 13 (13 duplicates) \\
\hline Electroencephalography & 15 & 12 (7 duplicates) & 43 & 11 (11 duplicates) & 42 & 11 (11 duplicates) \\
\hline Status epilepticus & 19 & 13 (9 duplicates) & 15 & 15 (15 duplicates) & 32 & 8 (8 duplicates) \\
\hline
\end{tabular}

*Duplicates: already found in previous searches 


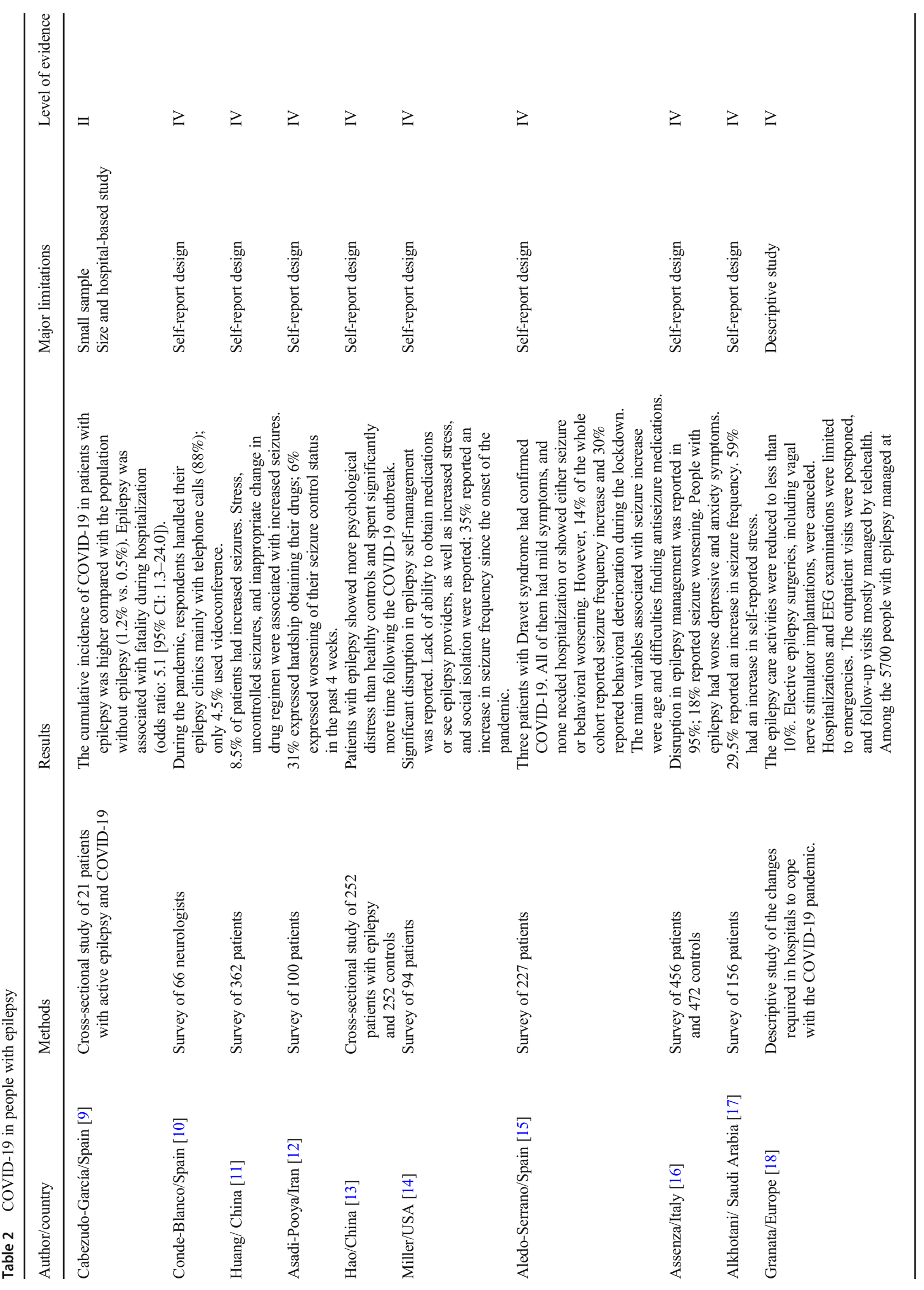




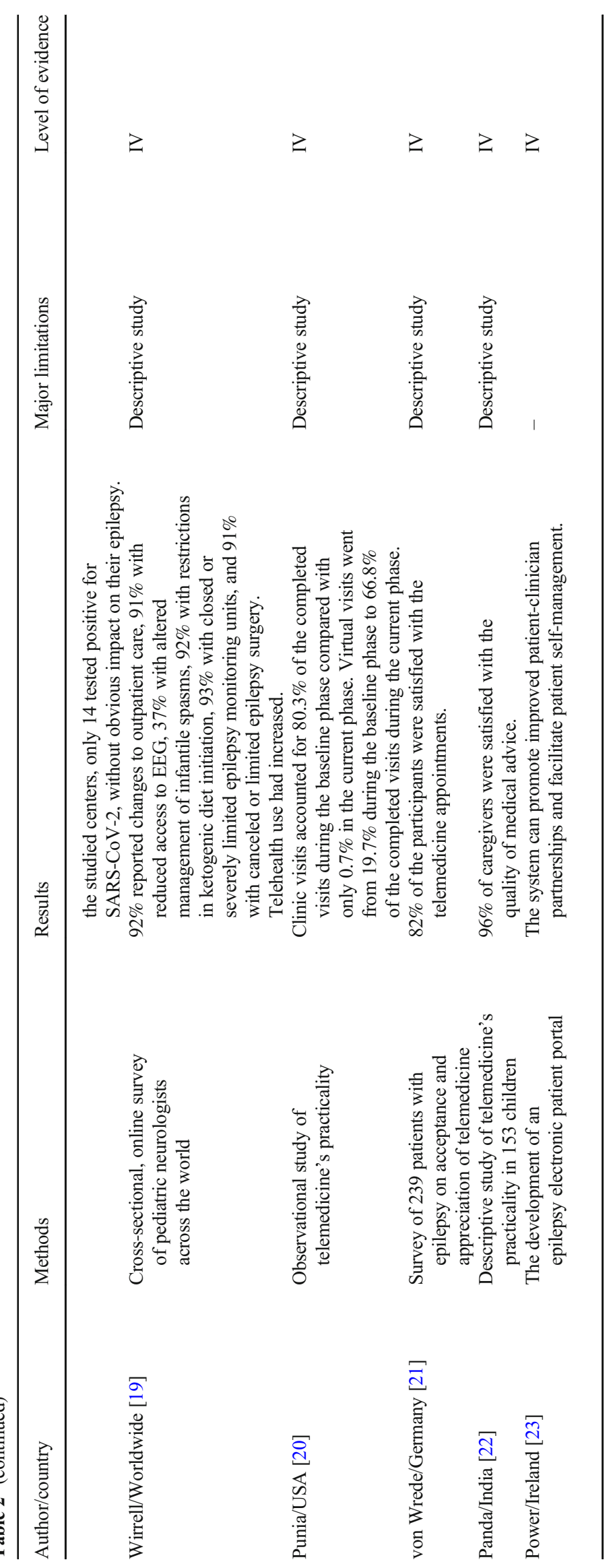




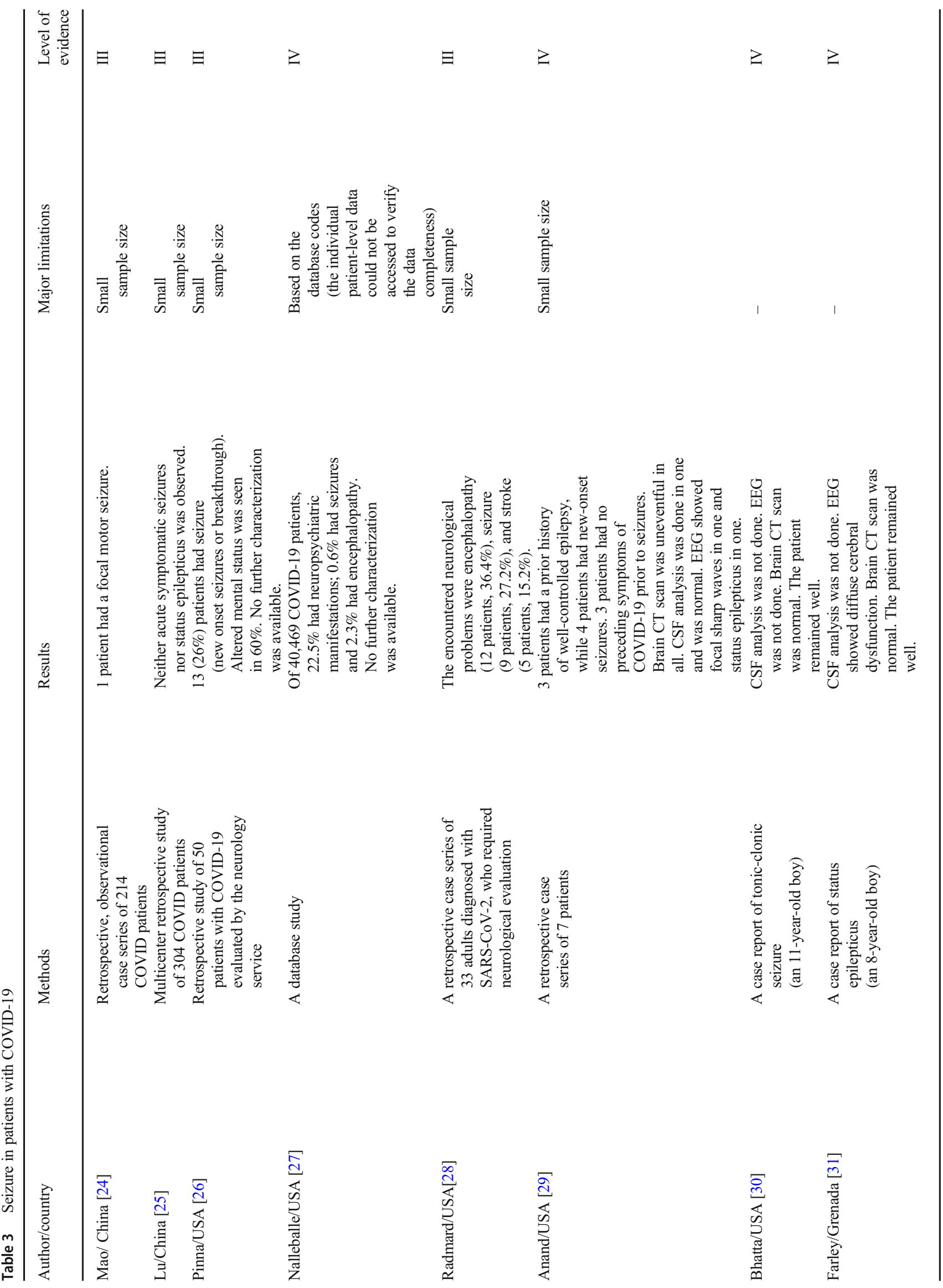




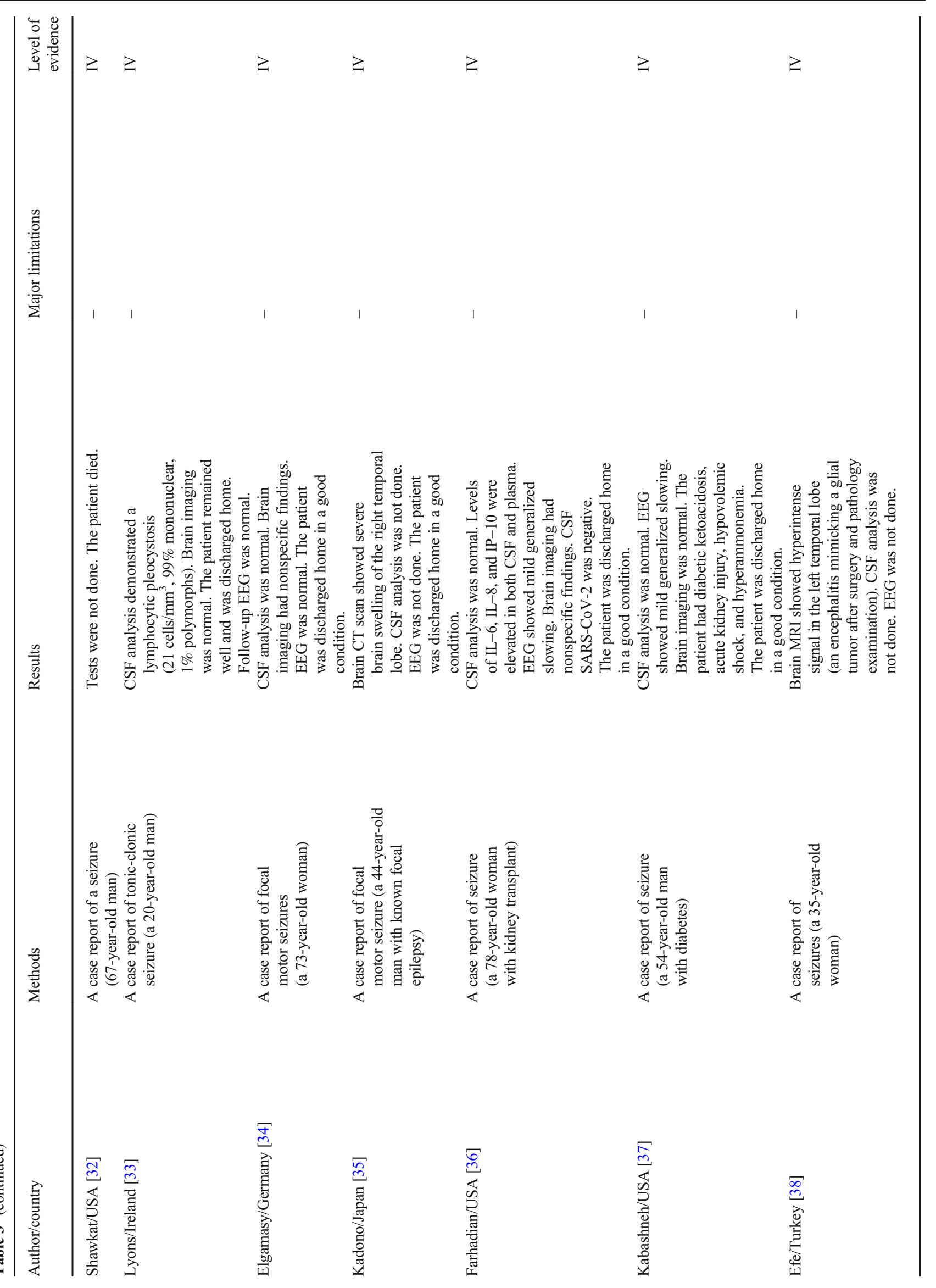




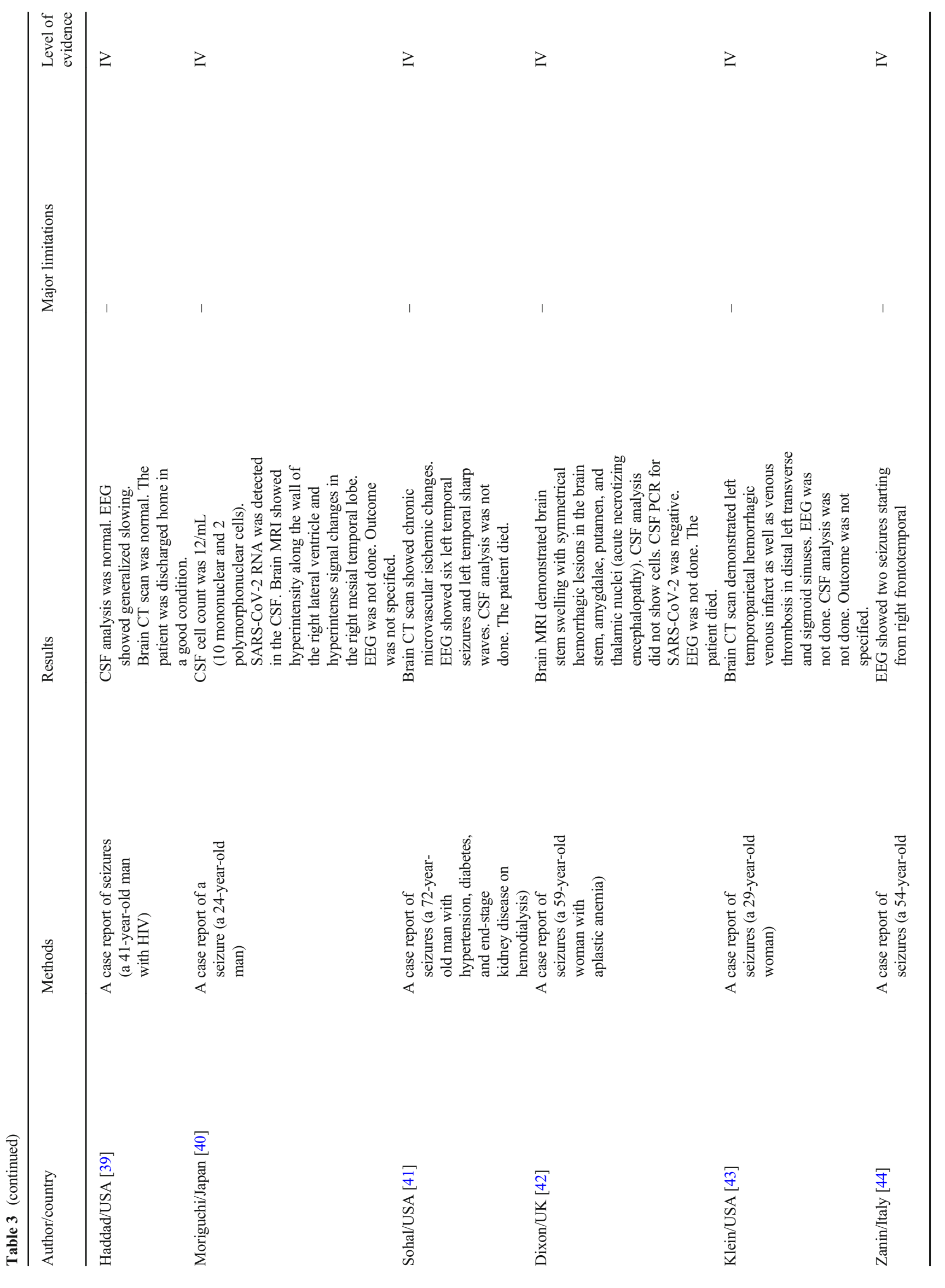




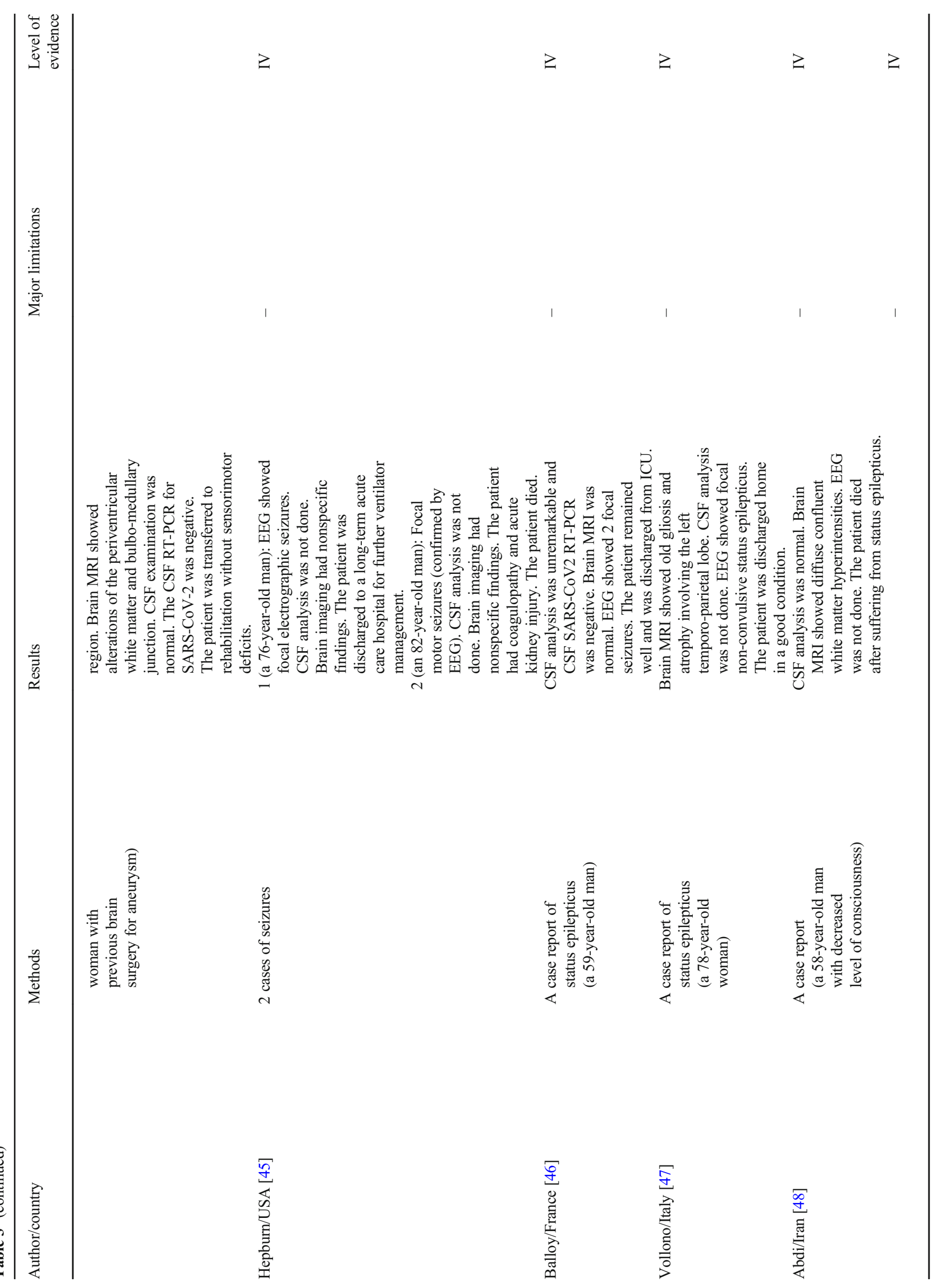




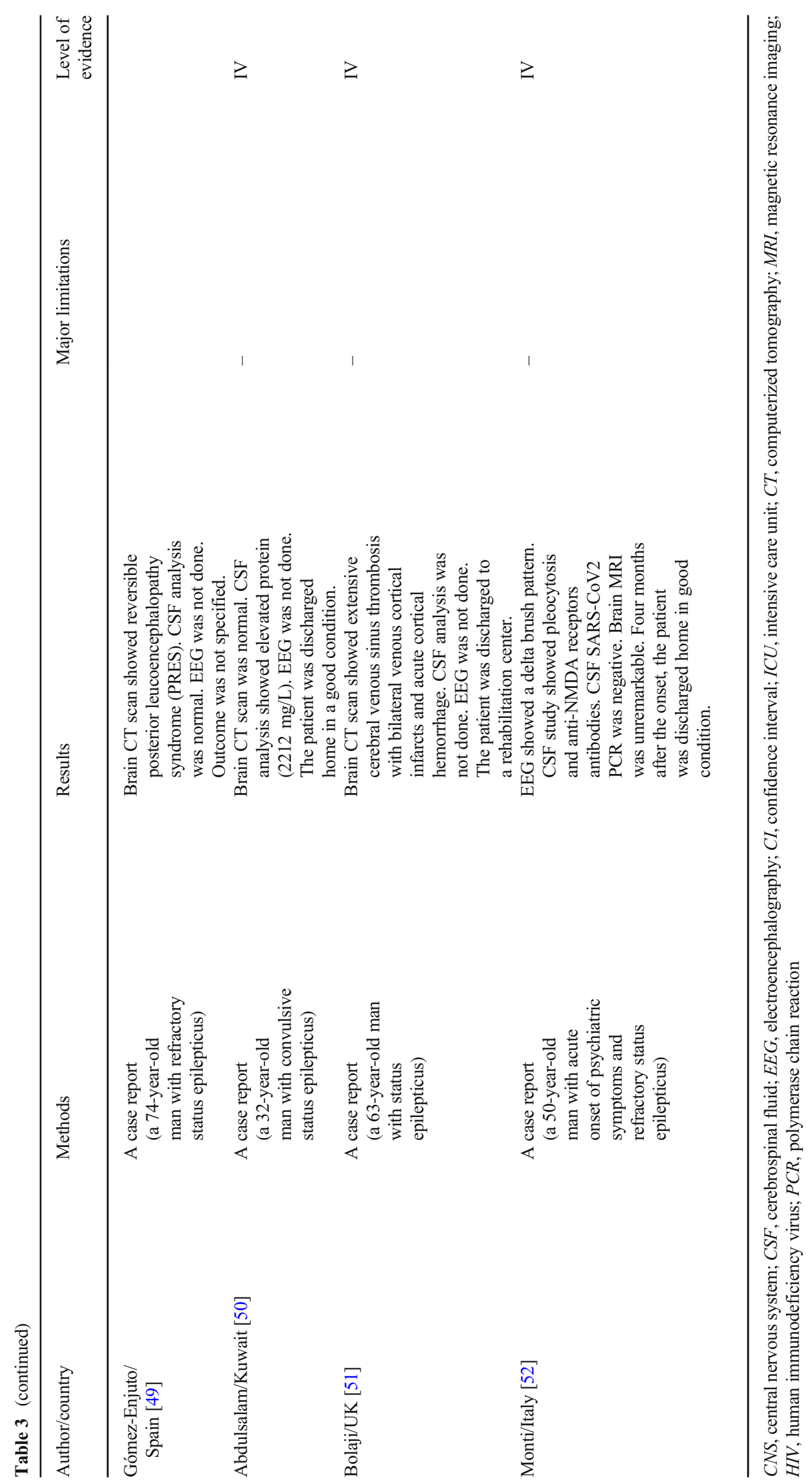




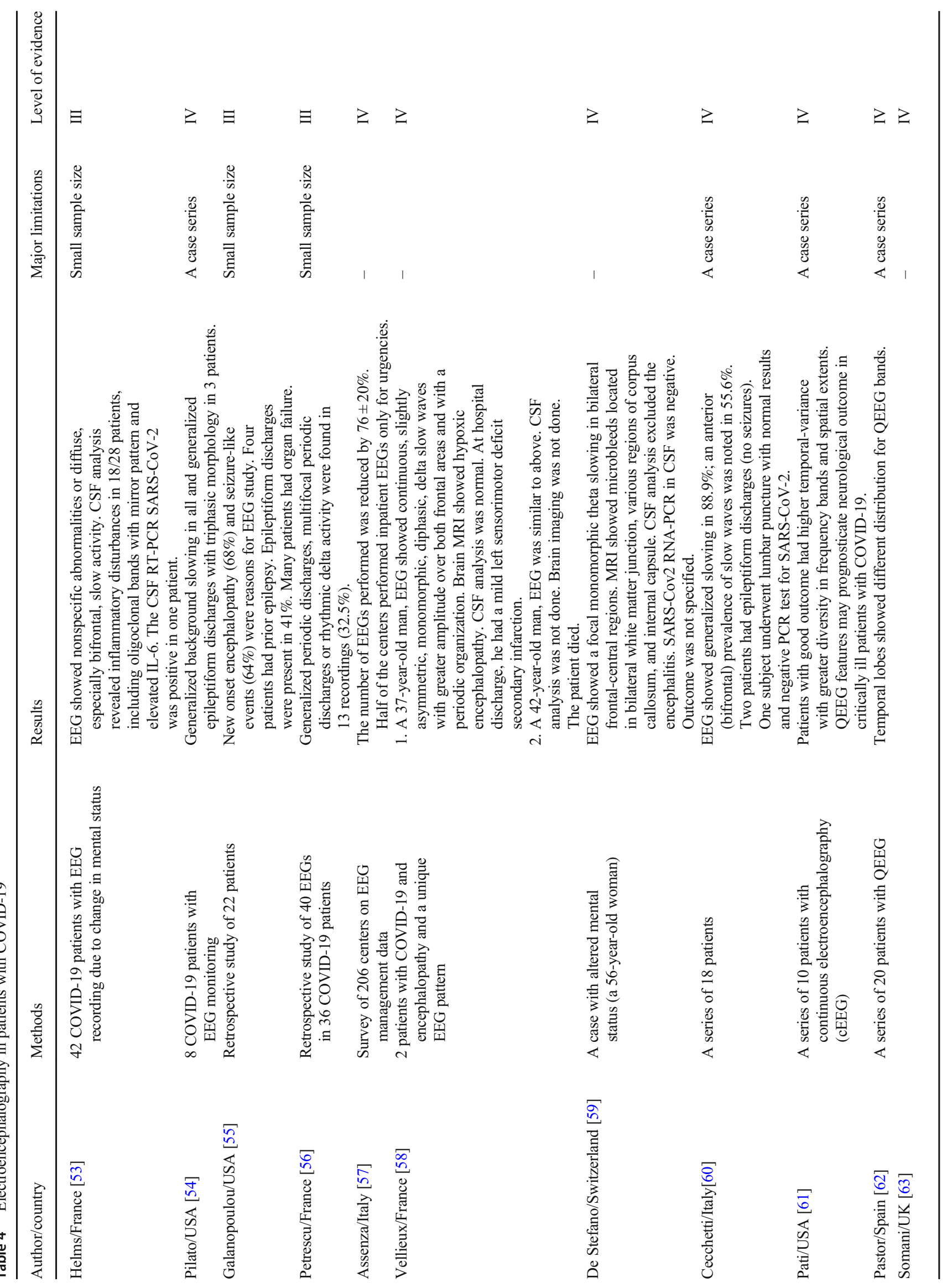




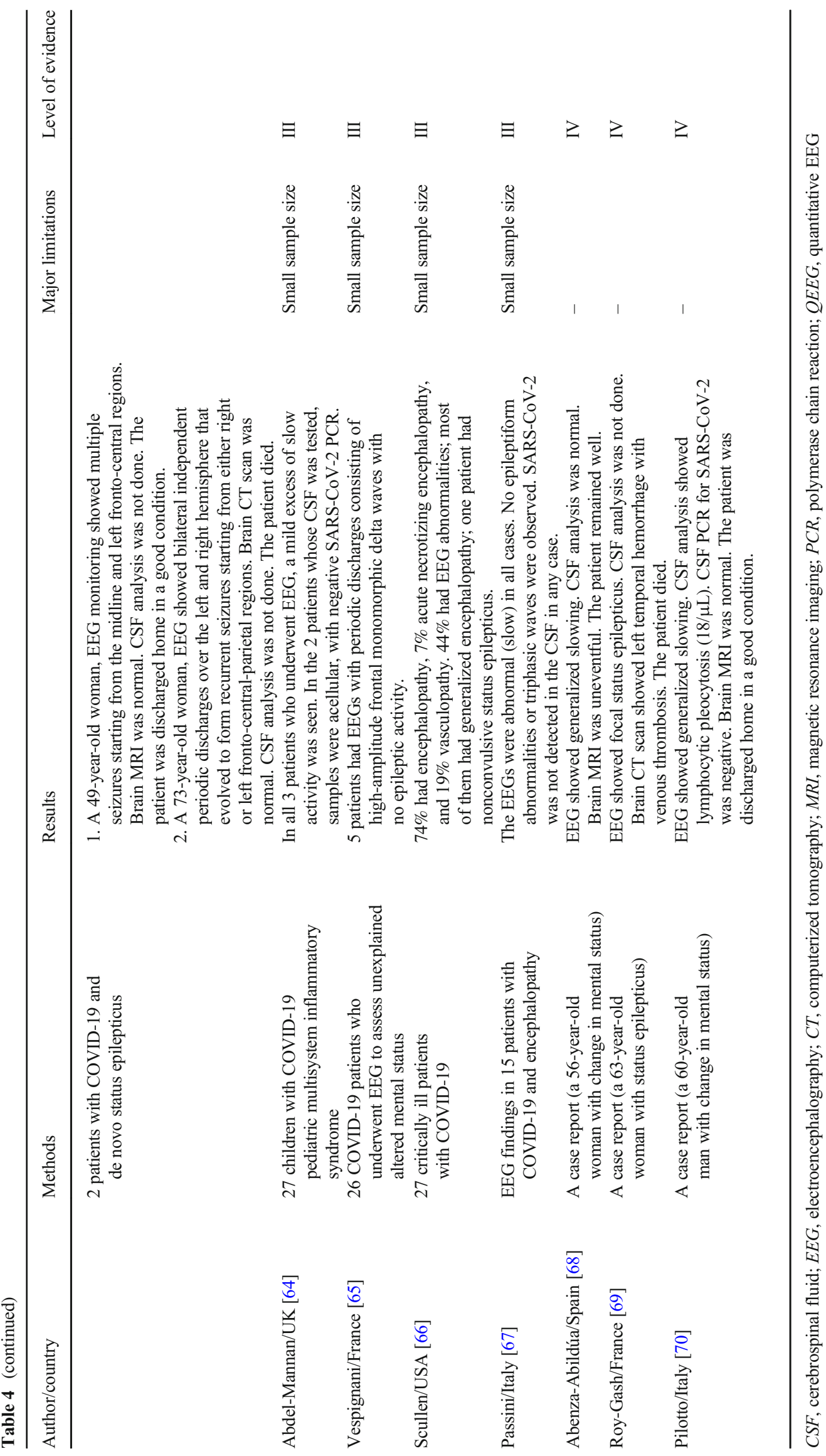


determine the etiology of the seizure and manage the cause (e.g., hypoxia and metabolic derangements) immediately. In addition to prolonged EEG monitoring, performing a thorough metabolic investigation, electrocardiogram, brain imaging, and a careful review of all medications (for adverse drug reactions and also drug-drug interactions) are necessary steps. CSF analysis is also necessary, at least to investigate other causes for acute symptomatic seizures that may happen concomitantly or that may mimic the clinical picture of COVID-19 (e.g., herpes simplex virus-1 encephalitis) [79]. In addition, it is often necessary to start an antiseizure medication (ASM) for a patient with COVID-19 and seizure(s); this is to abort prolonged seizures and also to prevent further seizures from happening [3]. It should be emphasized that patients with acute symptomatic seizures do not need long-term ASM therapy after the period of acute illness, unless a subsequent seizure happens [80]. For a comprehensive review on these issues, please refer to the references $[3,5,81]$.

\section{Conclusion}

\section{What we know and should pay more attention to}

Many PWE perceived significant disruption in the quality and availability of care to them, and some people reported increase in their seizure frequency since the onset of the pandemic. In addition, many PWE may have increased stress and anxiety. During pandemics and other difficult and catastrophic circumstances, healthcare workers should focus not only on seizure control status of their patients, but also on the mental health of PWE.

Telemedicine is a viable and helpful technology that may improve access to the needed care for PWE in these difficult times. The current COVID-19 pandemic is a strong call to develop the required infrastructure and to adopt the appropriate regulatory frameworks for implementation of telemedicine services globally [77].

De novo seizures may occur in people with COVID-19, and they may happen in a variety of forms (e.g., focal motor, tonic-clonic, convulsive status epilepticus, nonconvulsive status epilepticus, and post SARS-CoV2 autoimmune encephalitis associated with new-onset refractory status epilepticus (NORSE) [82, 83]). Furthermore, many patients with severe COVID-19 may have change in mental status. If a patient with COVID-19 develops a seizure or change in mental status, one should try to determine the etiology and manage the cause immediately. In addition to prolonged
EEG monitoring, performing a thorough metabolic investigation, electrocardiogram, brain imaging, CSF analysis, and a careful review of all medications are necessary steps.

\section{What we do not know yet and should be investigated further}

The evidence on the susceptibility of PWE to contracting COVID-19 and the consequences of this catastrophic disease in PWE is scarce. This significant concern should be addressed in the future through well-designed prospective cohort studies with all relevant confounders controlled.

SARS-CoV-2 RNA was detected in the CSF in two patients, but many other studies that tested for this had negative results. This is important to clarify the role of neurtropism and neuroinvasiveness of this virus in causing seizures in future studies.

It is not clear whether there is a unique EEG pattern for COVID-19 encephalopathy. It is helpful to describe the EEG findings in a systematic and consistent manner in order to characterize any possible distinguishing and/or prognosticating EEG patterns in patients with COVID-19.

Contributions Ali A. Asadi-Pooya: Designed and conceptualized the study; collected the data; analyzed the data; drafted and revised the manuscript.

Leila Simani, Mina Shahisavandi, Zohreh Barzegar: Collected the data; revised the manuscript.

Funding This study is supported by Shiraz University of Medical Sciences.

Data availability Data sharing is not applicable to this article.

\section{Compliance with ethical standards}

Conflict of interest Ali A. Asadi-Pooya, M.D.: Honoraria from Cobel Daruo, RaymandRad and Tekaje; Royalty: Oxford University Press (book publication). Others: none.

Ethical approval The Shiraz University of Medical Sciences Institutional Review Board approved this study and systematic review.

Research involving human participants and/or animals Not applicable.

Informed consent Not applicable.

Role of the funding source Shiraz University of Medical Sciences had no role in the study design; in the collection, analysis, and interpretation of data; in the writing of the report; and in the decision to submit the paper for publication.

None of the authors listed on the manuscript are employed by a government agency. All are academicians. None of the authors are submitting this manuscript as an official representative or on behalf of the government. 


\section{Appendix}

Table 5 American Academy of Neurology criteria for classification of evidence in studies of causation (Gronseth GS, Cox J, Gloss D, et al. on behalf of the Guideline Development, Dissemination, and Implementation
Subcommittee of the American Academy of Neurology. 2017. Clinical Practice Guideline Process Manual, 2017 ed. Minneapolis, MN: The American Academy of Neurology)

\begin{tabular}{ll}
\hline Classification & Criteria \\
\hline I & $\begin{array}{l}\text { Prospective cohort study with all relevant confounders controlled, masked or objective outcome assessments, and } \\
\text { a) } \leq 2 \text { primary outcomes, } \\
\text { b) clearly defined inclusion/exclusion criteria } \\
\text { c) } \geq 80 \% \text { study completion rate. }\end{array}$ \\
II & Retrospective cohort study or case-control study meeting all other class I criteria. \\
III & Cohort study or case-control study meeting all class I or II criteria except a, b, or c above. \\
IV & Studies not meeting class I, II, or III criteria \\
\hline
\end{tabular}

\section{References}

1. Rothan HA, Byrareddy SN (2020) The epidemiology and pathogenesis of coronavirus disease (COVID-19) outbreak. J Autoimmun 109:102433

2. Asadi-Pooya AA, Simani L (2020) Central nervous system manifestations of COVID-19: a systematic review. J Neurol Sci 413: 116832

3. Asadi-Pooya AA (2020) Seizures associated with coronavirus infections. Seizure 79:49-52

4. Bohmwald K, Gálvez NMS, Ríos M, Kalergis AM (2018) Neurologic alterations due to respiratory virus infections. Front Cell Neurosci 12:386

5. Asadi-Pooya AA, Attar A, Moghadami M, Karimzadeh I (2020) Management of COVID-19 in people with epilepsy: drug considerations. Neurol Sci:1-7. https://doi.org/10.1007/s10072-02004549-5

6. Hutton B, Salanti G, Caldwell DM, Chaimani A, Schmid CH, Cameron C, Ioannidis JPA, Straus S, Thorlund K, Jansen JP, Mulrow C, Catalá-López F, Gøtzsche PC, Dickersin K, Boutron I, Altman DG, Moher D (2015) The PRISMA extension statement for reporting of systematic reviews incorporating network metaanalyses of health care interventions: checklist and explanations. Ann Intern Med 162:777-784

7. Moher D, Liberati A, Tetzlaff J, Altman DG (2009) Preferred reporting items for systematic reviews and meta-analyses: the PRISMA statement. Ann Intern Med 151:264-269

8. Gronseth GS CJ, Gloss D, Merillat S, Dittman J, Armstrong MJ, on behalf of the Guideline Development, Dissemination, and Implementation Subcommittee of the American Academy of Neurology et al (2017) Clinical practice guideline process manual, 2017 edn. The American Academy of Neurology, Minneapolis, 2017

9. Cabezudo-García P, Ciano-Petersen NL, Mena-Vázquez N, PonsPons G, Castro-Sánchez MV, Serrano-Castro PJ (2020) Incidence and case fatality rate of COVID-19 in patients with active epilepsy. Neurology. https://doi.org/10.1212/WNL.0000000000010033

10. Conde-Blanco E, Centeno M, Tio E, Muriana D, García-Peñas JJ, Serrano $P$ et al (2020) Emergency implementation of telemedicine for epilepsy in Spain: results of a survey during SARS-CoV-2 pandemic. Epilepsy Behav 111:107211

11. Huang S, Wu C, Jia Y, Li G, Zhu Z, Lu K, Yang Y, Wang F, Zhu S (2020) COVID-19 outbreak: the impact of stress on seizures in patients with epilepsy. Epilepsia 61:1884-1893. https://doi.org/10. 1111/epi.16635

12. Asadi-Pooya AA, Farazdaghi M, Bazrafshan M (2020) Impacts of the COVID-19 pandemic on Iranian patients with epilepsy. Acta Neurol Scand 142:392-395. https://doi.org/10.1111/ane.13310

13. Hao X, Zhou D, Li Z, Zeng G, Hao N, Li E, Li W, Deng A, Lin M, Yan B (2020) Severe psychological distress among patients with epilepsy during the COVID-19 outbreak in southwest China. Epilepsia 61:1166-1173

14. Miller WR, Von Gaudecker J, Tanner A, Buelow JM (2020) Epilepsy self-management during a pandemic: experiences of people with epilepsy. Epilepsy Behav 111:107238

15. Aledo-Serrano Á, Mingorance A, Jiménez-Huete A, Toledano R, García-Morales I, Anciones C, Gil-Nagel A (2020) Genetic epilepsies and COVID-19 pandemic: lessons from the caregiver perspective. Epilepsia 61:1312-1314

16. Assenza G, Lanzone J, Brigo F, Coppola A, Di Gennaro G, Di Lazzaro V et al (2020) Epilepsy care in the time of COVID-19 pandemic in Italy: risk factors for seizure worsening. Front Neurol 11:737

17. Alkhotani A, Siddiqui MI, Almuntashri F, Baothman R (2020) The effect of COVID-19 pandemic on seizure control and self-reported stress on patient with epilepsy. Epilepsy Behav 112:107323

18. Granata T, Bisulli F, Arzimanoglou A, Rocamora R (2020) Did the COVID-19 pandemic silence the needs of people with epilepsy? Epileptic Disord. https://doi.org/10.1684/epd.2020.1175

19. Wirrell EC, Grinspan ZM, Knupp KG, Jiang Y, Hammeed B, Mytinger JR et al (2020) Care delivery for children with epilepsy during the COVID-19 pandemic: an international survey of clinicians. J Child Neurol 35:924-933

20. Punia V, Nasr G, Zagorski V, Lawrence G, Fesler J, Nair D, Najm I (2020) Evidence of a rapid shift in outpatient practice during the COVID-19 pandemic using telemedicine. Telemed J E Health 26: 1301-1303. https://doi.org/10.1089/tmj.2020.0150

21. von Wrede R, Moskau-Hartmann S, Baumgartner T, Helmstaedter C, Surges R (2020) Counseling of people with epilepsy via telemedicine: experiences at a German tertiary epilepsy center during the COVID-19 pandemic. Epilepsy Behav 112:107298

22. Panda PK, Dawman L, Panda P, Sharawat IK (2020) Feasibility and effectiveness of teleconsultation in children with epilepsy amidst the ongoing COVID-19 pandemic in a resource-limited country. Seizure 81:29-35

23. Power K, McCrea Z, White M, Breen A, Dunleavy B, O'Donoghue $S$ et al (2020) The development of an epilepsy electronic patient portal: facilitating both patient empowerment and remote clinician- 
patient interaction in a post-COVID-19 world. Epilepsia. https:// doi.org/10.1111/epi.16627

24. Mao L, Jin H, Wang M, Hu Y, Chen S, He Q et al (2020) Neurologic manifestations of hospitalized patients with coronavirus disease 2019 in Wuhan, China. JAMA Neurol 77:1-9

25. Lu L, Xiong W, Liu D, Liu J, Yang D, Li N, Mu J, Guo J, Li W, Wang G, Gao H, Zhang Y, Lin M, Chen L, Shen S, Zhang H, Sander JW, Luo J, Chen S, Zhou D (2020) New onset acute symptomatic seizure and risk factors in coronavirus disease 2019: a retrospective multicenter study. Epilepsia 61:e49-e53

26. Pinna P, Grewal P, Hall JP, Tavarez T, Dafer RM, Garg R, Osteraas ND, Pellack DR, Asthana A, Fegan K, Patel V, Conners JJ, John S, Silva ID (2020) Neurological manifestations and COVID-19: experiences from a tertiary care center at the frontline. J Neurol Sci 415: 116969

27. Nalleballe K, Reddy Onteddu S, Sharma R, Dandu V, Brown A, Jasti M et al (2020) Spectrum of neuropsychiatric manifestations in COVID-19. Brain Behav Immun S0889-1591(20):31008-31004

28. Radmard S, Epstein SE, Roeder HJ, Michalak AJ, Shapiro SD, Boehme A, Wilson TJ, Duran JC, Bain JM, Willey JZ, Thakur KT (2020) Inpatient neurology consultations during the onset of the SARS-CoV-2 New York City pandemic: a single center case series. Front Neurol 11:805

29. Anand P, Al-Faraj A, Sader E, Dashkoff J, Abdennadher M, Murugesan R et al (2020) Seizure as the presenting symptom of COVID-19: a retrospective case series. Epilepsy Behav 112: 107335. https://doi.org/10.1016/j.yebeh.2020.107335

30. Bhatta S, Sayed A, Ranabhat B, Bhatta RK, Acharya Y (2020) New-onset seizure as the only presentation in a child with COVID-19. Cureus 12:e8820

31. Farley M, Zuberi J (2020) COVID-19 precipitating status epilepticus in a pediatric patient. Am J Case Rep 21:e925776

32. Shawkat A, Merrell ET, Fadel GA, Amzuta I, Amin H, Shah AJ et al (2020) Multiple thrombotic events in a 67-year-old man 2 weeks after testing positive for SARS-CoV-2: a case report. Am J Case Rep 21:e925786

33. Lyons S, O'Kelly B, Woods S, Rowan C, Brady D, Sheehan G et al (2020) Seizure with CSF lymphocytosis as a presenting feature of COVID-19 in an otherwise healthy young man. Seizure 80:113114

34. Elgamasy S, Kamel MG, Ghozy S, Khalil A, Morra ME, Islam SMS (2020) First case of focal epilepsy associated with SARScoronavirus-2. J Med Virol. https://doi.org/10.1002/jmv.26113

35. Kadono Y, Nakamura Y, Ogawa Y, Yamamoto S, Kajikawa R, Nakajima Y, Matsumoto M, Kishima H (2020) A case of COVID-19 infection presenting with a seizure following severe brain edema. Seizure 80:53-55

36. Farhadian S, Glick LR, Vogels CBF, Thomas J, Chiarella J, Casanovas-Massana A, Zhou J, Odio C, Vijayakumar P, Geng B, Fournier J, Bermejo S, Fauver JR, Alpert T, Wyllie AL, Turcotte C, Steinle M, Paczkowski P, dela Cruz C, Wilen C, Ko AI, MacKay S, Grubaugh ND, Spudich S, Barakat LA (2020) Acute encephalopathy with elevated CSF inflammatory markers as the initial presentation of COVID-19. BMC Neurol 20:248

37. Kabashneh S, Ali H, Alkassis S (2020) Multi-organ failure in a patient with diabetes due to COVID-19 with clear lungs. Cureus 12:e8147

38. Efe IE, Aydin OU, Alabulut A, Celik O, Aydin K (2020) COVID19-associated encephalitis mimicking glial tumor. World Neurosurg 140:46-48

39. Haddad S, Tayyar R, Risch L, Churchill G, Fares E, Choe M, Montemuro P (2020) Encephalopathy and seizure activity in a COVID-19 well controlled HIV patient. IDCases 21:e00814

40. Moriguchi T, Harii N, Goto J, Harada D, Sugawara H, Takamino J, Ueno M, Sakata H, Kondo K, Myose N, Nakao A, Takeda M, Haro H, Inoue O, Suzuki-Inoue K, Kubokawa K, Ogihara S, Sasaki T,
Kinouchi H, Kojin H, Ito M, Onishi H, Shimizu T, Sasaki Y, Enomoto N, Ishihara H, Furuya S, Yamamoto T, Shimada S (2020) A first case of meningitis/encephalitis associated with SARS-Coronavirus-2. Int J Infect Dis 94:55-58

41. Sohal S, Mansur M (2020) COVID-19 presenting with seizures. IDCases 20:e00782

42. Dixon L, Varley J, Gontsarova A, Mallon D, Tona F, Muir D et al (2020) COVID-19-related acute necrotizing encephalopathy with brain stem involvement in a patient with aplastic anemia. Neurol Neuroimmunol Neuroinflamm 7:e789

43. Klein DE, Libman R, Kirsch C, Arora R (2020) Cerebral venous thrombosis: a typical presentation of COVID-19 in the young. J Stroke Cerebrovasc Dis 29:104989

44. Zanin L, Saraceno G, Panciani PP, Renisi G, Signorini L, Migliorati $\mathrm{K}$, Fontanella MM (2020) SARS-CoV-2 can induce brain and spine demyelinating lesions. Acta Neurochir 162:1491-1494

45. Hepburn M, Mullaguri N, George P, Hantus S, Punia V, Bhimraj A et al (2020) Acute symptomatic seizures in critically ill patients with COVID-19: is there an association? Neurocrit Care:1-5. https://doi. org/10.1007/s12028-020-01006-1

46. Balloy G, Mahé PJ, Leclair-Visonneau L, Péréon Y, Derkinderen P, Magot A et al (2020) Non-lesional status epilepticus in a patient with coronavirus disease 2019. Clin Neurophysiol 131:2059-2061

47. Vollono C, Rollo E, Romozzi M, Frisullo G, Servidei S, Borghetti A, Calabresi P (2020) Focal status epilepticus as unique clinical feature of COVID-19: a case report. Seizure 78:109-112

48. Abdi S, Ghorbani A, Fatehi F (2020) The association of SARSCoV-2 infection and acute disseminated encephalomyelitis without prominent clinical pulmonary symptoms. J Neurol Sci 416:117001

49. Gómez-Enjuto S, Hernando-Requejo V, Lapeña-Motilva J, Ogando-Durán G, Fouz-Ruiz D, Domingo-García J, RodríguezGarcía E, Cemillán-Fernández CA (2020) Verapamil as treatment for refractory status epilepticus secondary to PRES syndrome on a SARS-Cov-2 infected patient. Seizure 80:157-158

50. Abdulsalam MA, Abdulsalam AJ, Shehab D (2020) Generalized status epilepticus as a possible manifestation of COVID-19. Acta Neurol Scand. https://doi.org/10.1111/ane.13321

51. Bolaji P, Kukoyi B, Ahmad N, Wharton C (2020) Extensive cerebral venous sinus thrombosis: a potential complication in a patient with COVID-19 disease. BMJ Case Rep 13:e236820

52. Monti G, Giovannini G, Marudi A, Bedin R, Melegari A, Simone AM, Santangelo M, Pignatti A, Bertellini E, Trenti T, Meletti S (2020) Anti-NMDA receptor encephalitis presenting as new onset refractory status epilepticus in COVID-19. Seizure 81:18-20

53. Helms J, Kremer S, Merdji H, Schenck M, Severac F, Clere-Jehl R, Studer A, Radosavljevic M, Kummerlen C, Monnier A, Boulay C, Fafi-Kremer S, Castelain V, Ohana M, Anheim M, Schneider F, Meziani F (2020) Delirium and encephalopathy in severe COVID19: a cohort analysis of ICU patients. Crit Care 24:491

54. Pilato MS, Urban A, Alkawadri R, Barot NV, Castellano JF, Rajasekaran $\mathrm{V}$ et al (2020) EEG findings in coronavirus disease. J Clin Neurophysiol. https://doi.org/10.1097/WNP. 0000000000000752

55. Galanopoulou AS, Ferastraoaru V, Correa DJ, Cherian K, Duberstein S, Gursky J, Hanumanthu R, Hung C, Molinero I, Khodakivska O, Legatt AD, Patel P, Rosengard J, Rubens E, Sugrue W, Yozawitz E, Mehler MF, Ballaban-Gil K, Haut SR, Moshé SL, Boro A (2020) EEG findings in acutely ill patients investigated for SARS-CoV-2/COVID-19: a small case series preliminary report. Epilepsia Open 5:314-324

56. Petrescu AM, Taussig D, Bouilleret V (2020) Electroencephalogram (EEG) in COVID-19: a systematic retrospective study. Neurophysiol Clin 50:155-165

57. Assenza G, Lanzone J, Ricci L, Boscarino M, Tombini M, Galimberti CA et al (2020) Electroencephalography at the time of 
Covid-19 pandemic in Italy. Neurol Sci:1-6. https://doi.org/10. 1007/s10072-020-04546-8

58. Vellieux G, Rouvel-Tallec A, Jaquet P, Grinea A, Sonneville R, d'Ortho MP (2020) COVID-19 associated encephalopathy: is there a specific EEG pattern? Clin Neurophysiol 131:1928-1930

59. De Stefano P, Nencha U, De Stefano L, Mégevand P, Seeck M (2020) Focal EEG changes indicating critical illness associated cerebral microbleeds in a Covid-19 patient. Clin Neurophysiol Pract 5:125-129

60. Cecchetti G, Vabanesi M, Chieffo R, Fanelli G, Minicucci F, Agosta F et al (2020) Cerebral involvement in COVID-19 is associated with metabolic and coagulation derangements: an EEG study. J Neurol:1-5. https://doi.org/10.1007/s00415-020-09958-2

61. Pati S, Toth E, Chaitanya G (2020) Quantitative EEG markers to prognosticate critically ill patients with COVID-19: a retrospective cohort study. Clin Neurophysiol 131:1824-1826

62. Pastor J, Vega-Zelaya L, Martín Abad E (2020) Specific EEG encephalopathy pattern in SARS-CoV-2 patients. J Clin Med 9:1545

63. Somani S, Pati S, Gaston T, Chitlangia A, Agnihotri S (2020) De Novo Status Epilepticus in patients with COVID-19. Ann Clin Transl Neurol. https://doi.org/10.1002/acn3.51071

64. Abdel-Mannan O, Eyre M, Löbel U, Bamford A, Eltze C, Hameed $B$ et al (2020) Neurologic and radiographic findings associated with COVID-19 infection in children. JAMA 77:1-6

65. Vespignani H, Colas D, Lavin BS, Soufflet C, Maillard L, Pourcher $\mathrm{V}$ et al (2020) Report of EEG Finding on Critically Ill Patients with COVID-19. Ann Neurol. https://doi.org/10.1002/ana.25814

66. Scullen T, Keen J, Mathkour M, Dumont AS, Kahn L (2020) Coronavirus 2019 (COVID-19)-associated Encephalopathies and cerebrovascular disease: the New Orleans experience. World Neurosurg S1878-8750(20):31163-31163

67. Pasini E, Bisulli F, Volpi L, Minardi I, Tappatà M, Muccioli L, Pensato U, Riguzzi P, Tinuper P, Michelucci R (2020) EEG findings in COVID-19 related encephalopathy. Clin Neurophysiol 131: 2265-2267

68. Abenza-Abildúa MJ, Novo-Aparicio S, Moreno-Zabaleta R, Algarra-Lucas MC, Rojo Moreno-Arcones B, Salvador-Maya MÁ, Navacerrada-Barrero FJ, Ojeda-Ruíz de Luna J, PérezLópez C, Fraile-Vicente JM, Suárez-García I, Suarez-Gisbert E, Palacios-Castaño JA, Ramirez-Prieto MT (2020) Encephalopathy in severe SARS-CoV2 infection: inflammatory or infectious? Int J Infect Dis 98:398-400

69. Roy-Gash F, Marine M, Jean-Michel D, Herve V, Raphael B, Nicolas E (2020) COVID-19-associated acute cerebral venous thrombosis: clinical, CT, MRI and EEG features. Crit Care 24:419

70. Pilotto A, Odolini S, Masciocchi S, Comelli A, Volonghi I, Gazzina $S$ et al (2020) Steroid-responsive encephalitis in coronavirus disease 2019. Ann Neurol. https://doi.org/10.1002/ana.25783

71. Hirsch LJ, LaRoche SM, Gaspard N, Gerard E, Svoronos A, Herman ST et al (2013) American clinical neurophysiology
Society's standardized critical care EEG terminology: 2012 version. J Clin Neurophysiol 30:1-27

72. Kubota T, Kuroda N (2020) Exacerbation of neurological symptoms and COVID-19 severity in patients with preexisting neurological disorders and COVID-19: a systematic review. Clin Neurol Neurosurg:106349. https://doi.org/10.1016/j.clineuro.2020.106349

73. Lai SL, Hsu MT, Chen SS (2005) The impact of SARS on epilepsy: the experience of drug withdrawal in epileptic patients. Seizure 14: 557-561

74. World Health Organization (2020) Mental health and psychosocial considerations during the COVID-19 outbreak, 18 March 2020. World Health Organization, Geneva

75. Salari N, Hosseinian-Far A, Jalali R, Vaisi-Raygani A, Rasoulpoor S, Mohammadi M, Rasoulpoor S, Khaledi-Paveh B (2020) Prevalence of stress, anxiety, depression among the general population during the COVID-19 pandemic: a systematic review and meta-analysis. Glob Health 16:57

76. Tombini M, Assenza G, Quintiliani L, Ricci L, Lanzone J, Ulivi M, di Lazzaro V (2020) Depressive symptoms and difficulties in emotion regulation in adult patients with epilepsy: association with quality of life and stigma. Epilepsy Behav 107:107073

77. Ohannessian R, Duong TA, Odone A (2020) Global telemedicine implementation and integration within health systems to fight the COVID-19 pandemic: a call to action. JMIR Public Health Surveill 6:e18810

78. Haddad N, Grant I, Eswaran H (2015) Telemedicine for patients with epilepsy: a pilot experience. Epilepsy Behav 44:1-4

79. Lovati C, Osio M, Pantoni L (2020) Diagnosing herpes simplex-1 encephalitis at the time of COVID-19 pandemic. Neurol Sci 41: 1361-1364

80. Bergey GK (2016) Management of a first seizure. Continuum (Minneap Minn) 22(1 Epilepsy):38-50

81. French JA, Brodie MJ, Caraballo R, Devinsky O, Ding D, Jehi L, Jette N, Kanner A, Modi AC, Newton CR, Patel AA, Pennell PB, Perucca E, Sander JW, Scheffer IE, Singh G, Williams E, Wilmshurst J, Cross JH (2020) Keeping people with epilepsy safe during the COVID-19 pandemic. Neurology 94:1032-1037

82. Dono F, Carrarini C, Russo M, De Angelis MV, Anzellotti F, Onofrj $\mathrm{M}$ et al (2020) New-onset refractory status epilepticus (NORSE) in post SARS-CoV-2 autoimmune encephalitis: a case report. Neurol Sci:1-4. https://doi.org/10.1007/s10072-020-04846$\mathrm{z}$

83. Emami A, Fadakar N, Akbari A, Lotfi M, Farazdaghi M, Javanmardi F, Rezaei T, Asadi-Pooya AA (2020) Seizure in patients with COVID-19. Neurol Sci 41:3057-3061

Publisher's note Springer Nature remains neutral with regard to jurisdictional claims in published maps and institutional affiliations. 